\title{
Application of Economic Analyses in U.S. Managed Care Formulary Decisions: A Private Payer's Experience
}

JOHN B. WATKINS, RPh, MPH, BCPS; MICHAEL E. MINSHALL, MPH; and SEAN D. SULLIVAN, RPh, MS, PhD

\begin{abstract}
BACKGROUND: Promoting use of pharmacoeconomic models by formulary reviewers is a goal of the Academy of Managed Care Pharmacy (AMCP) Format for Formulary Submissions, but relatively few decision makers use such models, and many doubt that they provide meaningful input.

OBJECTIVE: To demonstrate how sophisticated disease-based pharmacoeconomic models can aid formulary decision makers when long-term outcomes data are lacking.

METHODS: The Center for Outcomes Research (CORE) Diabetes Model (CDM), a published, validated Markov pharmacoeconomic model that projects clinical and economic endpoints, was used to model the cost-effectiveness of exenatide, a new injectable antidiabetic agent that enhances glucose-dependent insulin secretion, in a standard cohort of type 2 diabetes patients (mean body mass index $[\mathrm{BMI}]=27.5 \pm 3 \mathrm{~kg} / \mathrm{m}^{2}$ ), compared with a modified obese cohort (mean $\mathrm{BMI}=35 \pm 3 \mathrm{~kg} / \mathrm{m}^{2}$ ) that was otherwise demographically identical at baseline to the standard cohort. The standard cohort was assumed to maintain baseline weight during treatment, and the modified obese cohort was assumed to experience weight loss of approximately $9 \%$ (mean $=3 \mathrm{~kg} / \mathrm{m}^{2}$ ), with corresponding improvements in blood pressure, lowdensity lipoprotein cholesterol, and triglycerides. We selected a 30-year time horizon because it was the time interval during which the CDM predicted most of the subjects would have died, and the costs obtained thus reasonably projected lifetime total direct medical costs for these cohorts. While treatment options certainly will change over a 30 -year period, our goal was to estimate the incremental effect of exenatide over other available therapies.

RESULTS: The model predicted reduced long-term treatment costs in obese patients, driven by an $11 \%$ decrease in cardiovascular disease burden and derived from the presumed weight loss. The incremental cost-effectiveness ratio (ICER) for adding exenatide over 3 years was $\$ 35,000 /$ quality-adjusted life-year (QALY). Using a 30-year horizon, ICER values were $\$ 13,000 /$ QALY versus insulin, $\$ 32,000$ versus generic glyburide, and $\$ 16,000$ versus no additional treatment. Exenatide dominated pioglitazone. By comparison, the 30-year ICER for exenatide versus insulin in the nonobese cohort was $\$ 33,000$. These results were presented to the pharmacy and therapeutics (P\&T) committee and influenced its decision to add exenatide to the drug formulary. While our modeling assumed certain patient characteristics (e.g., obesity, need of further A1c reduction at baseline, motivation to lose weight), the P\&T committee imposed only a step-therapy requirement to try either metformin or a sulfonylurea before trying exenatide and did adopt a nonspecific requirement for physician reauthorization of refills before the fourth pharmacy claim for exenatide.
\end{abstract}

CONCLUSIONS: Disease-based pharmacoeconomic models may help thirdparty payers project costs and be particularly useful when only data from short-term clinical trials are available. In the present case, the pharmacy staff of a health plan used a pharmacoeconomic model for drug treatment of type 2 diabetes provided by the manufacturer as part of the AMCP Format dossier process to project cost outcomes for exenatide, adjunct injectable therapy for patients taking metformin and/or sulfonylurea. The P\&T committee approved the drug for inclusion in the drug formulary based in part on the results of the pharmacoeconomic model produced from the cost inputs entered into the model by the health plan pharmacists.

KEYWORDS: Exenatide; Pharmacoeconomic models; Drug formulary; AMCP Format

J Manag Care Pharm. 2006;12(9):726-35
S ince the first publication of the Academy of Managed Care Pharmacy (AMCP) Format for Formulary Submissions in 2000 , one of its goals has been to encourage the meaningful consideration of pharmacoeconomic modeling results as part of the formulary review process. ${ }^{1}$ The information that can be gleaned from well-designed models extends far beyond simply projecting the fiscal impact of a new product on pharmacy budgets. It suggests the extent to which drug cost may be offset by reductions in other medical costs, evaluates cost-effectiveness of the new treatment, and in some cases helps identify target subpopulations in whom the drug will have a greater benefit and/or a smaller number needed to treat (NNT), thus improving incremental cost-effectiveness ratios (ICERs) in such patients. The importance of economic models will increase as more biologics and other high-cost medications come to market since therapeutic selection often involves choices among drugs that are covered under both pharmacy and medical benefits by most U.S. payers. In this environment, health plan pharmacy benefit managers will require sound data to persuade actuaries, brokers, customers, health plan chief financial officers, and other executives of the need to expand pharmacy budgets based on demonstrated medical cost offsets.

Many emerging drugs are designed to treat chronic conditions and will be taken over many years, perhaps for the lifetime of the patient. In such cases, some of the most important proposed benefits of the drug cannot be measured in clinical trials because they will not be observed for years or decades. The budget impact of new drugs and other technology will become increasingly important, and payers will demand more than theoretical projections to support the proposed value of these agents. Until evidence can be accumulated in administrative

\section{Authors}

JOHN B. WATKINS, RPh, MPH, BCPS, is pharmacy manager, formulary development, at Premera Blue Cross and a clinical associate professor of pharmacy, University of Washington; MICHAEL E. MINSHALL, MPH, is principal, health economics and outcomes research, IMS Health, and an adjunct professor, Department of Public Health, Indiana University School of Medicine; SEAN D. SULLIVAN, RPh, MS, PhD, is a professor of pharmacy and public health and director, Pharmaceutical Outcomes Research and Policy Program, University of Washington.

AUTHOR CORRESPONDENCE: John B. Watkins, RPh, MPH, BCPS, Pharmacy Manager, Formulary Development, Premera Blue Cross, 7001 220th St., SW, Mountlake Terrace, WA 98043-2124. Tel: (425) 918-5146; Fax: (425) 918-5944; E-mail: john.watkins@premera.com

Copyright $\odot$ 2006, Academy of Managed Care Pharmacy. All rights reserved. 
claims or from postmarketing clinical studies, sophisticated disease-based economic models can be substituted. For this reason, payers and policymakers need to consider providing appropriate incentives to encourage improved modeling efforts.

Monitoring the value of drugs used to treat type 2 diabetes will provide excellent opportunities to apply advanced pharmacoeconomic modeling technologies. The aging population will increase the prevalence of individuals at risk of developing this disease. Use of these drugs will be increased further by shifts in diabetes clinical practice guidelines toward earlier diagnosis and more aggressive treatment, with the result that more individuals will be treated with more drugs for longer portions of their lives. Meanwhile, several new classes of drugs are appearing: inhaled insulins (Exubera), incretins (exenatide and liraglutide), and the new class of dipeptidyl peptidase IV inhibitors (sitagliptin and vildagliptin). With all these changes, payers will face complex formulary choices and will need to consider appropriate steptherapy algorithms.

Langley and Sullivan first published guidelines for pharmacoeconomic evaluation by U.S. private payers in 1996. ${ }^{2}$ From this concept, Mather et al. drafted a set of guidelines for implementation at Regence BlueShield, where the guidelines improved the efficiency of the evidence-gathering process employed by the plan's pharmacy staff. ${ }^{3}$ Although the pharmaco- economic modeling presented in these early dossiers left much to be desired, it was a step in the right direction.

Upon publication of the first version of the AMCP Format in 2000, Premera Blue Cross, a 1.6- million-member commercial participating provider option health plan operating in Washington and Alaska, adopted a similar process in 2001. Premera pharmacy staff has archived all dossiers and economic models received since that time for formal evaluation, preliminary results of which suggest that the quality of the dossiers continues to be inconsistent. ${ }^{4-5}$ The quality of dossiers does seem to be better for innovative products, and a number of useful models have been submitted; the results have been included in the formulary decision-making process at Premera. The AMCP Format includes a synthesis of modeling standards developed by the Panel on Cost-Effectiveness in Health and Medicine ${ }^{6}$ and will be updated to reflect the ongoing work of others, such as the International Society for Pharmacoeconomics and Outcomes Research (ISPOR).

Many health plans now use the AMCP Format as a tool to improve efficiency in gathering clinical information, but relatively few decision makers give serious consideration to the models offered with product dossiers. There is a perception that these models do not provide useful input to the average managed care organization (MCO). Several reasons for this have been suggested. ${ }^{7}$ Many MCO pharmacists believe that manufacturersponsored economic evaluations will be biased toward the product being evaluated. There is some evidence to support this belief. A recent systematic review of published analyses reported an odds ratio of 2:1 that the product would cost less than
$\$ 20,000$ per quality-adjusted life-year (QALY) gained when the manufacturer had funded the study. ${ }^{8}$ In our experience, although one can become reasonably adept at spotting the most obvious biases without extensive pharmacoeconomic training, most health plan formulary support personnel have yet to attempt this on a regular basis. Other reasons for the lack of use of modeling include perceived lack of relevance, sociocultural attitudes, and a lack of understanding of the methodology and lack of expertise needed to evaluate models. ${ }^{7}$

From these empirical observations, it is evident that dossier models must adapt to a variety of skill levels among the target audience, and assumptions biased toward the product must be eliminated. Furthermore, the attributes of different health plans and the conditions under which managed care pharmacists conduct formulary reviews vary considerably. These factors make customization of the model presentation and input variables for the individual health plan a necessity. This customization is a 2 -way process. The model builder and the end user must communicate clearly if the customized model is to have a reasonable chance of meeting the customer's needs.

The foregoing discussion demonstrates that economic modeling can meet a variety of customer needs for budget and cost-effectiveness forecasting, but it should be noted that a well-designed disease-based model can predict long-term clinical outcomes as well. Especially with newer drugs, it is often the case that the most important clinical outcomes of the therapy have not been experimentally verified. In some cases, the required clinical trials can never be performed because they would involve exposing subjects to ethically unacceptable levels of risk or to treatments whose efficacy is known to be less than proven alternatives. Moreover, these clinical trials would need to run 10 to 15 years or longer, making them prohibitively expensive for most manufacturers. When experimental data are lacking or ambiguous, models can sometimes be used to predict the relevant outcomes. ${ }^{10}$ Both developer and end user should be aware of the limitations of such use, and they should carefully evaluate the assumptions, particularly when projecting longterm outcomes from short-term data.

The challenge of modeling a new product for which there are no long-term study results becomes even more difficult when the manufacturer is inexperienced in presenting pharmaceutical outcomes to the customer. The biotechnology revolution has opened the door for many smaller innovative companies to develop potentially valuable products. Such companies may license or comarket the product through a more experienced vendor, but doing so is certainly not a requirement. Consultants are available to assist them in developing meaningful outcomes presentations that articulate the value of the new product. In fact, a creative manufacturer may be in a better position to develop new ways of demonstrating a product's value since the manufacturer does not have old templates or historical inertia.

Amylin Pharmaceuticals, a biopharmaceutical manufacturer, 
launched its first 2 products, pramlintide ${ }^{11}$ and exenatide,$^{12}$ in March and April 2005, respectively. Several months before the launch of these products, representatives of Amylin Pharmaceuticals asked Premera Blue Cross pharmacy staff for modeling suggestions. After these discussions, Amylin licensed access to the Center for Outcomes Research (CORE) Diabetes Model (CDM) and made the model available to Premera as part of the product dossier submission.

The primary purpose of this paper is to illustrate, using a case-study approach, how use of an economic model as well as effective communication between the manufacturer of a new agent and a health plan can support a comprehensive health technology assessment, which then leads to a decision on the appropriate place in therapy and formulary positioning of exenatide. It is important to point out that this paper is not intended to describe and detail the CORE model structure (published elsewhere) or to focus on the model parameters and cost-effectiveness findings that were considered by the pharmacy and therapeutics (P\&T) committee. Rather, we describe how the model pathways and relevant parameters selected by the health plan were used to estimate cost-effectiveness from the perspective of Premera Blue Cross and that these estimates were presented to the P\&T committee as part of the complete product monograph.

\section{Setting}

In 2001, Premera Blue Cross established an independent formulary review process based on the AMCP Format. ${ }^{13}$ Pharmacists review the manufacturer's dossier, conduct independent literature research, and prepare evidence summaries in the form of formulary monographs. The P\&T committee members, leading physicians and pharmacists from various parts of Washington and Alaska, select formulary products, determine the positioning of products in copayment tiers, and approve criteria to determine medical necessity. No voting member of this committee may be a regular employee of Premera or have a financial interest in any health plan. Members declare conflicts of interest before product discussions and then refrain from voting in that instance.

Amylin Pharmaceuticals is a biopharmaceutical company specializing in genetically engineered peptides, the first two of which, exenatide and pramlintide, were approved by the U.S. Food and Drug Administration (FDA) in 2005. Before launching these products, Amylin made a significant research effort to determine customer requirements, including the need for pharmacoeconomic modeling, by conducting market surveys, advisory board meetings, and individual interviews with key customers.

\section{Exenatide}

Exenatide is the first incretin agent that mimics the enhance- ment of glucose-dependent insulin secretion and several other antihyperglycemic actions of incretins, a group of hormones that are released into the circulation by the gut. First discovered in the saliva of Gila monsters, it is now produced synthetically. ${ }^{12}$ Exenatide is approved by the FDA for use as adjunctive therapy to improve glycemic control in patients with type 2 diabetes mellitus who are taking metformin, a sulfonylurea, or a combination of metformin and a sulfonylurea, but have not achieved adequate glycemic control. Along with small reductions in glycosylated hemoglobin (HbAlc) levels (0.5-0.9), a statistically significant maximum weight loss of 2-3 kg from baseline body weight was observed in exenatide clinical trials. ${ }^{14}$ Compared with placebo (metformin alone), exenatide in combination with metformin at 30 weeks of follow-up was associated with a net weight loss of $1.3 \mathrm{~kg}(1.3 \%)$ at the $5-\mathrm{mg}$ dose twice daily or of $2.5 \mathrm{~kg}(2.5 \%)$ at the 10-mg dose twice daily. Weight loss was less for exenatide in combination with sulfonylurea. For exenatide in combination with metformin and sulfonylurea, the mean weight loss at week 30 was only $0.7 \mathrm{~kg}$ $(0.7 \%)$ for either $5 \mathrm{mg}$ twice daily or $10 \mathrm{mg}$ twice daily, compared with placebo.

Various studies have examined the effect of weight loss on cardiovascular risk factors such as blood pressure and lipid levels. In 2003, Anderson et al. published a systematic review and meta-analysis of these studies, from which they predicted that a $10 \%$ reduction in body weight would produce decreases of $11 \%$ in low-density lipoprotein cholesterol (LDL-C), 26.7\% in triglyceride levels, and $8.1 \%$ in systolic blood pressure. ${ }^{15}$

Notwithstanding the extent to which exenatide is discussed in this paper, the following should not be construed as advocating its use over that of any other competing antidiabetic agent. Our intent is rather to demonstrate how economic modeling was used to support the manufacturer's application for formulary review. However, submission of a dossier with cost-effectiveness modeling does not guarantee review of any product by the Premera P\&T committee.

\section{CORE Diabetes Model}

We employed the CDM, a published, validated Markov process model that uses surrogate clinical endpoints, such as HbAlc, LDL-C, and body mass index (BMI) to project long-term clinical endpoints such as myocardial infarction, stroke, endstage renal disease, neuropathy, and retinopathy. The CDM also projects economic endpoints, of which drug cost, total cost of care, life expectancy, and QALY are of greatest interest to our formulary reviewers. Previous publications have described the structure ${ }^{16}$ data inputs, and validation ${ }^{17}$ of this model.

Other validated models have also been published, including the Archimedes model and others that use newer methodology. ${ }^{18}$ Premera does not advocate the use of any particular model because all of them are capable of performing the analysis required for our project. It is not the purpose of this report to 
critique these models; however, we did take the limitations of the CDM and of Markov models in general into consideration.

The CDM is consistent with recently published American Diabetes Association computer-based modeling guidelines and principles for diabetes. ${ }^{19} \mathrm{HbAlc}$-dependent adjustments for the risks of developing complications in type 1 diabetes mellitus were derived predominantly from the Diabetes Control and Complications Trial $^{20}$ and for type 2 diabetes mellitus from the United Kingdom Prospective Diabetes Study (UKPDS). ${ }^{21}$ Other studies used to construct the CDM have been previously described. ${ }^{16}$

The CDM predicts the development and progression of type 2 diabetes over varying time horizons (1-100 years), using best available published clinical and epidemiological data. The model has a standard Markov structure, combined with Monte Carlo simulation and the use of tracker variables, that allows for the development and progression of multiple complications in an individual patient over time, while at the same time overcoming the memory-free properties of traditional Markov models.

A Markov model consists of a series of states corresponding to clinical situations, e.g., healthy, ambulatory ill, or hospitalized. Each state is populated with a certain number of hypothetical patients. The model repeats a number of cycles, with individuals moving from one state to another at each cycle, on the basis of transition probabilities determined from epidemiological or clinical studies. When an individual moves to a particular state, a traditional Markov model has no memory of the path that individual took to get there. This is a major limitation when modeling a long-term chronic disease such as diabetes, but the CORE model works around this by storing the information in tracker variables. Incidence and progression of comorbidities can thus be followed and coordinated with the main diabetes model. The process of deciding which transition probabilities and risk adjustments from the published literature to incorporate into the CDM was undertaken by a multinational expert panel comprising 2 health economists and 4 physicians convened by the model developers, and is described in detail elsewhere. ${ }^{16}$

The CDM structure includes 15 submodels that simulate diabetes-related complications (angina, cataract, congestive heart failure, foot ulcer and amputation, hypoglycemia, ketoacidosis, lactic acidosis, macular edema, myocardial infarction, nephropathy, neuropathy, peripheral vascular disease, retinopathy, and stroke) along with all-cause mortality. All submodels run parallel to each other to allow hypothetical patients to develop complications concomitantly where appropriate. When published data indicate that the presence of one complication increases the probability of another complication, the increased probability for the second complication is incorporated into the model as time progresses through the simulation exercise.

The CDM was validated through 66 separate analyses that covered the published studies used to create the model (second

\section{(TABLE 1$)$ Characteristics of the Simulated Population Cohorts}

\begin{tabular}{|c|c|c|}
\hline Characteristic & \begin{tabular}{|l|} 
Standard CDM \\
UKPDS Cohort
\end{tabular} & $\begin{array}{c}\text { Customized } \\
\text { Obese Cohort }\end{array}$ \\
\hline \multicolumn{3}{|l|}{ Demographic } \\
\hline Age at start (years) & $53( \pm 10)$ & $53( \pm 10)$ \\
\hline Duration of diabetes (years) & $8( \pm 5)$ & $8( \pm 5)$ \\
\hline Female(\%) & 50 & 50 \\
\hline White (\%) & 81 & 81 \\
\hline Black (\%) & 8 & 8 \\
\hline Hispanic (\%) & 1 & 1 \\
\hline Asian/Pacific Islander (\%) & 10 & 10 \\
\hline \multicolumn{3}{|l|}{ Baseline risk factor } \\
\hline$\overline{A l c}(\%)$ & $8.5( \pm 1)$ & $8.5( \pm 1)$ \\
\hline Systolic BP (mm Hg) & $135( \pm 10)$ & $145( \pm 10)$ \\
\hline Total cholesterol (mg/dL) & $207( \pm 30)$ & $217( \pm 30)$ \\
\hline HDL-C (mg/dL) & $41( \pm 5)$ & $41( \pm 5)$ \\
\hline LDL-C (mg/dL) & $134( \pm 20)$ & $144( \pm 20)$ \\
\hline Triglycerides (mg/dL) & $207( \pm 30)$ & $230( \pm 30)$ \\
\hline BMI $\left(\mathrm{Kg} / \mathrm{m}^{2}\right)$ & $27.5( \pm 3)$ & $35( \pm 3)$ \\
\hline Smokers (\%) & 20 & 20 \\
\hline Cigarettes/day & 10 & 10 \\
\hline Alcohol consumption (ounces/week) & 5 & 5 \\
\hline
\end{tabular}

Baseline cardiovascular disease complication

\begin{tabular}{l|l|l}
\hline Myocardial infarction (\%) & 0 & 0 \\
\hline Angina (\%) & 0 & 0 \\
\hline PVD (\%) & 0 & 0 \\
\hline Stroke (\%) & 0 & 0 \\
\hline Heart failure (\%) & 0 & 0 \\
\hline Atrial filbrillation (\%) & 3 & 3 \\
\hline Left ventricular hypertrophy (\%) & 3 & 3
\end{tabular}

Baseline microvascular complication

\begin{tabular}{l|c|c}
\hline Mircroalbuminuria (\%) & 18 & 18 \\
\hline Proteinuria (\%) & 2 & 2 \\
\hline End stage renal disease (\%) & 0 & 0 \\
\hline Diabetic retinopathy (\%) & 36 & 36
\end{tabular}

Alc=glycosylated hemoglobin; $B M I=$ body mass index; $B P=$ blood pressure; $C D M=C O R E$ Diabetes Model; HDL-C=high-density lipoprotein cholesterol;

$L D L-C=$ low-density lipoprotein cholesterol; $P V D=$ peripheral vascular disease; UKPDS $=$ United Kingdom Prospective Diabetes Study.

order), along with published clinical and epidemiological studies not used in creating the model (third order). ${ }^{17}$ Studies were chosen that described a wide range of diabetic populations, treatments, product delivery settings, and resulting outcomes. Selected studies included the necessary intermediate parameters and were also chosen based on the breadth of coverage for 


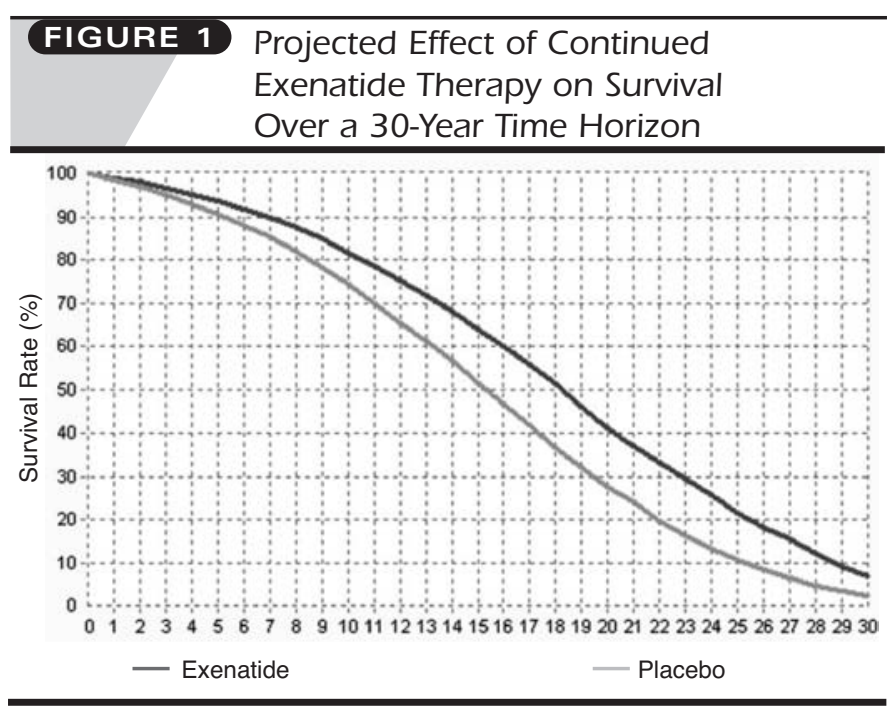

specific diabetic complications (e.g., Wisconsin Epidemiological Study of Diabetic Retinopathy for retinopathy outcomes) and time periods (from 1960 to 2003), as clinical treatments and algorithms have evolved significantly over time.

\section{Exenatide Modeling Parameters}

To test the hypothesis that weight reduction would improve long-term outcomes in patients treated with exenatide, 2 of the authors (Watkins and Sullivan) used the CDM to compare 2 cohorts of 5,000 type 2 diabetes patients. We began with a hypothetical cohort supplied by the model developer. This group, which we labeled the "standard" cohort and used as a comparison group, was built by the developer using data from the UKPDS study population and had a baseline mean BMI = $27.5 \pm 3 \mathrm{~kg} / \mathrm{m}^{2}$. From this template, we built a modified "obese" cohort that had similar demographics, except that mean BMI was $35 \pm 3 \mathrm{~kg} / \mathrm{m}^{2}$. Both groups had mean baseline HbAlc levels of $8.5 \%$. Our obese cohort had modestly higher baseline mean blood pressure, total cholesterol, and LDL-C, as would be expected with the much greater body weight. Table 1 shows the baseline input values assigned to each cohort.

The standard cohort was assumed to maintain baseline weight during treatment and the obese group was assumed to experience a mean weight reduction of 3 BMI units, about 15 to 20 pounds (8.5\%) in a subject of average adult height, with resulting mean decreases of $10 \mathrm{~mm} \mathrm{Hg}$ in systolic blood pressure, $20 \mathrm{mg} / \mathrm{dL}$ in LDL-C, and $59 \mathrm{mg} / \mathrm{dL}$ in triglyceride levels. Corresponding decreases in the nonobese cohort were assumed to be the CDM standard defaults: $1.3 \mathrm{~mm} \mathrm{Hg}$ in systolic blood pressure, $1.6 \mathrm{mg} / \mathrm{dL}$ in LDL-C, and $39 \mathrm{mg} / \mathrm{dL}$ in triglyceride levels. All other parameters were identical in both groups, using the defaults supplied with the CDM. It should be noted that all these inputs were either standard values that the CDM model developers have taken from the literature of published diabetes outcome trials or modifications to those values based on published literature. ${ }^{16}$ Blonde et al. reported that 314 subjects (57.0\% of 551 subjects randomized to exenatide and who completed 82 weeks of therapy) lost an average of 10 pounds (about 5\%) over 82 weeks and their mean weight was still decreasing at the end of this period. ${ }^{22}$ On this basis, we assumed a long-term mean weight loss of 15 to 20 pounds (8.5\%). In programming our cohort to lose $70 \%$ more weight than the $5 \%$ mean pounds reported at 82 weeks, we hypothesized that patient selection criteria would include good adherence to dietary as well as medication use instructions. If these individuals continued to maintain a mean weight of 15 to 20 fewer pounds than they would have had without exenatide treatment, we wanted to see what effect this weight loss would have on long-term outcomes predicted by the CDM. These inputs were selected by the payer, in consultation with CORE and with local diabetes experts from whom the payer routinely seeks advice and feedback. None of the input variable assumptions were supplied or influenced by the product manufacturer.

All patients were assumed to be receiving monotherapy with generic metformin at baseline, based on the proposed step-therapy edit recommended by the Premera reviewers on completion of the clinical section of the formulary monograph. This algorithm is also congruent with the advice of local diabetes opinion leaders we consulted and with a recent analysis of Premera diabetes drug use that found that a majority of Premera diabetes patients were currently filling metformin prescriptions.

Recognizing that pharmacy staff at a typical health plan would devote only minimal time to manipulating such a model, we kept the test scenarios simple. In each scenario, 1 additional therapy (active drug or metformin alone ["placebo"]) was added to the treatment groups. We modeled head-to-head comparisons of exenatide versus the following alternative treatments: once-daily insulin glargine, pioglitazone $30 \mathrm{mg}$, generic glyburide $15 \mathrm{mg}$, or no additional treatment. (To shorten the text in our tables, the "no additional treatment option" is labeled "placebo." It should be noted that all the hypothetical patients continued to receive metformin. In this respect, our design resembles an add-on clinical trial.) Drug acquisition costs were based on approximate average ingredient cost per year from actual Premera claims experience from January through December 2005 for all members covered by the plan's 3-tier formulary. These prices represent the average allowed charge that includes the member cost share and thus represents the payment amounts actually received by pharmacies from the member and the health plan rather than just the amount paid by the plan. The approximate annual costs modeled were exenatide, $\$ 2,600$; insulin glargine, $\$ 1,300$; pioglitazone, $\$ 2,300$; and generic glyburide, $\$ 3,000$.

We selected a time horizon of 30 years after experimenting with values ranging from 3 to 50 years. We chose 30 years 


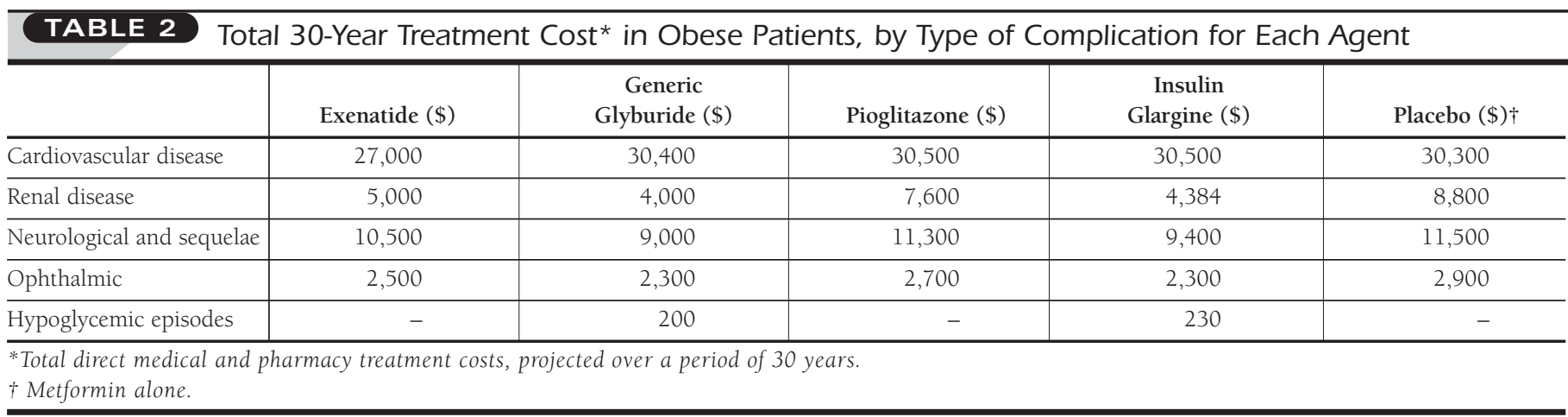

\section{TABLE 3 Pairwise Pharmacoeconomic Comparison of Alternative Therapeutic Choices Versus Exenatide in Patients Currently Receiving Metformin}

\begin{tabular}{|c|c|c|c|c|}
\hline & $\begin{array}{c}\text { Generic } \\
\text { Glyburide }\end{array}$ & Pioglitazone & $\begin{array}{l}\text { Insulin } \\
\text { Glargine }\end{array}$ & Placebo $\dagger$ \\
\hline \multicolumn{5}{|l|}{ Model inputs } \\
\hline Cost per treatment year $(\$)$ & 300 & 2,300 & 1,300 & 0 \\
\hline Mean reduction in $\mathrm{AlC}(\%)$ & -0.9 & -0.6 & -2.0 & 0 \\
\hline \multicolumn{5}{|c|}{ Model endpoints (incremental outcome for exenatide, compared with alternative agent) } \\
\hline Change in life expectancy (years) & 0.6 & 0.9 & 0.7 & 1.5 \\
\hline Change in QALYs* & 1.0 & 1.2 & 1.3 & 1.7 \\
\hline Incremental total direct cost (\$) & 31,000 & $-1,000$ & 16,000 & 27,000 \\
\hline Incremental cost-effectiveness (\$/QALY) & 32,000 & Dominates & 13,000 & 16,000 \\
\hline \multicolumn{5}{|c|}{$\begin{array}{l}\text { * Health state utilities incorporated into the CDM were derived from UKPDS data. } \\
+ \text { Metformin alone. } \\
\text { Alc=glycosylated hemoglobin; CDM=CORE Diabetes Model; QALY=quality-adjusted life-year; UKPDS=United Kingdom Prospective Diabetes Study. }\end{array}$} \\
\hline
\end{tabular}

because it was the time interval during which the CDM predicted most of the subjects would have died, and the costs obtained thus reasonably project lifetime total direct medical costs for these cohorts. (Figure 1 shows examples typical of the survival curves we saw during this testing.) In these tests, the main difference between the survival curves occurred in the 6-to-30year range, so this is the time frame in which the CDM is most useful in modeling the chosen population of type 2 patients diagnosed in middle age.

Our model scenario envisioned type 2 diabetics on optimal doses of metformin at baseline who still needed to reduce HbAlc levels by 1 to 2 percentage points (these patients will need at least 1 additional agent added to their metformin regimens). In this situation, the most likely alternatives to adding exenatide would be a sulfonylurea, a thiazolidinedione, or basal insulin. We selected glyburide (identified as "glibenclamide" in the $\mathrm{CDM}$, according to European generic nomenclature), pioglitazone (Actos) and insulin glargine (Lantus) as examples of each of these classes. The CDM calculated projected total treatment costs by organ system, and we used these costs as proxies for severity of cardiovascular, renal, neurological (including sequelae of peripheral neuropathy, such as foot ulcers and limb amputations), and ophthalmic disease. Projected cost of treating hypoglycemia was also reported to the end user in the model outputs.

\section{Results}

Population characteristics were modeled based on the "UKPDS General" cohort template supplied with the CDM. We cloned and modified this cohort to produce our "Obese Cohort" (mean BMI $=35 \pm 3 \mathrm{~kg} / \mathrm{m}^{2}$ ). The resulting demographics and risk factor inputs for our standard and obese cohorts are shown in Table 1.

\section{Effect on Long-term Disease Burden}

The CDM projected treatment costs for exenatide with metformin, each of the comparator agents with metformin, and no additional treatment (placebo) with metformin. These results are displayed in Table 2. The model predicted an $11 \%$ reduction in cardiovascular disease cost with exenatide compared with the alternatives, whereas insulin glargine and 
glyburide had more effect on nephropathy and complications of neuropathy.

\section{Cost-effectiveness of Exenatide}

Pair-wise comparisons were performed between exenatide and each alternative drug over a 30-year time horizon, assuming continued benefit from treatment with exenatide over this length of time. Exenatide was found to dominate pioglitazone and to be incrementally cost effective (ICER $<\$ 50,000 / \mathrm{QALY})$ compared with insulin glargine and no additional treatment, whereas the ICER for glyburide was somewhat higher, reflecting the very low cost of this generic product and its potency in lowering HbAlc. These pair-wise comparisons are summarized in Table 3.

Generally, payers are more interested in short-term rather than long-term treatment costs. Therefore, we examined the effect of time horizon on exenatide incremental cost-effectiveness compared with no additional (metformin only) treatment. The results are displayed in Figure 2. With a 3-year horizon, the predicted ICER was \$35,000/QALY gained. This dropped steadily in the 5 to 20-year time frame, when most of these patients would be aged 60 to 75 years, and the complications of diabetes begin to have a major impact on patients' health and survival. The ICER reached $\$ 16,000$ per QALY at 20 years and did not further decrease when the calculations were extended to 30 years.

The CDM can also use the projected impact of various treatment interventions to plot survival curves. Figure 1 shows the incremental impact of adding exenatide to patients in our obese cohort compared with continuing metformin monotherapy. The impact of exenatide on survival is small during the first decade of treatment but increases in the second decade, where the difference in percentage of original patients still surviving exceeds $10 \%$ for several years.

\section{Discussion}

Our modeling scenarios and results were described in the pharmacoeconomic section of the formulary monograph and the key findings included in a slide presentation to the P\&T committee members before they voted on the formulary status of exenatide. On the basis of the clinical and pharmacoeconomic evidence gathered, pharmacy staff recommended addition of exenatide to the Premera 3-tier formulary with step-therapy restrictions, requiring prior trial of metformin, consistent with our modeling assumptions and the product label. The P\&T committee accepted this recommendation and added to the prior authorization criteria a 1-time review of each patient's response to exenatide by the prescriber. Documentation of this review will be required before the fourth prescription claim for exenatide is allowed for payment. The P\&T committee did not want to specify the magnitude or nature of the patient response, using the logic that it was sufficient to remind prescribers to follow up with the patient, assuming that the physicians would check Alc, assess weight loss and other responses, and adjust therapy as required.

Incomplete clinical data on a new product is a common problem for formulary reviewers, particularly when the drug has a unique mechanism of action. The pressure to be first to market leads manufacturers to design shorter clinical trials when possible and launch the product as quickly as possible. Such trials usually do not provide adequate evidence to predict long-term clinical outcomes without recourse to data from a secondary source. When a product is fast-tracked, even the Phase 3 trials are often pending publication when the initial formulary review by the P\&T committee is conducted.

Through use of the AMCP Format, we are asking manufacturers to help us identify responders to their drug, thereby narrowing the target population and improving the predicted NNT and cost-effectiveness. The case of exenatide was particularly enigmatic. It had a novel pharmacologic mechanism that promised improved glycemic control with less risk of hypoglycemia, but no outcome studies existed. Exenatide has been observed to produce modest weight loss in the range of $5 \%$ or $5 \mathrm{~kg}$ in a population that is otherwise likely to gain weight, especially with tight glycemic control. ${ }^{22}$ Some local diabetes opinion leaders were optimistic about the potential benefits of exenatide, but none could articulate how to identify the ideal patient for it.

On the basis of the modest weight loss observed in placebocontrolled phase 3 trials $^{23-25}$ and in a 6-month head-to-head comparison trial of exenatide with insulin glargine, ${ }^{26}$ we hypothesized that the likely candidate for exenatide therapy would be obese. If such a patient were able to achieve even a modest weight loss, the long-term effects should be beneficial. The CDM provided a convenient means of testing our hypothesis.

Our modeling supports this hypothesis, though it still does not provide a specific means of identifying responders, especially since most of this population is overweight. Combining our modeling results with the data from clinical trials, we suggest that, until further evidence is available, candidates for exenatide should be obese, in need of further $\mathrm{HbAlc}$ reduction at baseline, motivated to lose weight, compliant, willing to self-inject the medication, and able to tolerate significant nausea for the first few weeks of therapy. This rationale was accepted by the P\&T committee, but the committee did not impose any of these conditions as criteria for prior authorization.

\section{Time Horizon and Payer Perspective}

For reasons previously stated, most of our cost-effectiveness calculations used a 30-year time horizon. It is less necessary to model shorter horizons, since the investigators have already published longitudinal data from open-label extensions of the phase 3 trials to 82 weeks $^{22}$ and are continuing to collect these results. It has been argued that employers and payers should be interested in more than a 3-year horizon when optimizing 
diabetes treatment because of the long-term consequences of the disease. ${ }^{27}$ When one considers the demographics of diabetes, this should resonate with large sophisticated employers since the individuals most likely to suffer increased burden of illness are middle-aged workers in their peak productive years. As improved diabetes therapies continue to be developed, newer drugs may replace exenatide in treatment algorithms, but it is logical that, in the meantime, we should select agents that are likely to produce improved long-term outcomes.

The value of exenatide is very much dependent on the perspective of the payer. Neumann and Sullivan recently commented that the caution of most U.S. payers in adopting cost-effectiveness analyses as a part of health technology assessment is one of the major factors differentiating our health care system from that of other nations with national single-payer systems where the payer's interests align much better with a societal perspective. They predict that our system will, of necessity, move toward an understanding of value in health that is more like those of other nations, though the change will probably be subtle and incremental and that the AMCP Format will play an important role in this transformation. ${ }^{28}$ From society's viewpoint, a 30-year time frame is of great interest, and we believe that payers should consider longer-term outcomes as well. Health plans have a fiduciary responsibility to purchasers and enrollees to seek the best value for their limited financial resources. For a disease such as diabetes, long-term outcomes must be examined to determine which treatment alternative offers best value for a given patient. Employers interested in productivity and retention of senior staff should take notice, since optimal management of diabetes can delay the development of complications that will reduce employees' survival (Figure 1) and their work effectiveness later, often during their peak productive years.

However, since U.S. payers traditionally focus on 1- to 3year time frames corresponding to their budget and contracting cycles, not wishing to ignore their needs, we evaluated the impact of time horizon on the ICER for exenatide versus no additional treatment (see Figure 2). The ICER at 1 year was slightly more than double the 30-year value and still within the limits generally considered to be cost effective. We noted that the exenatide product dossier for U.S. private payers also contains a shorter time horizon budget impact model prepared by CORE at the request of Amylin Pharmaceuticals that projects the expected number of exenatide patients, total drug spending, and per-member-per-month cost for the drug over its first 5 years on the market.

\section{Limitations}

One limitation of this study is that we did not model inhaled insulin (Exubera), the first inhaled insulin product now available in the U.S. market; inhaled insulin may become a popular alternative to other second-line preinsulin medications. Limited

\section{FIGURE 2 Effect of Time Horizon on Calculated} Incremental Cost-effectiveness Ratio

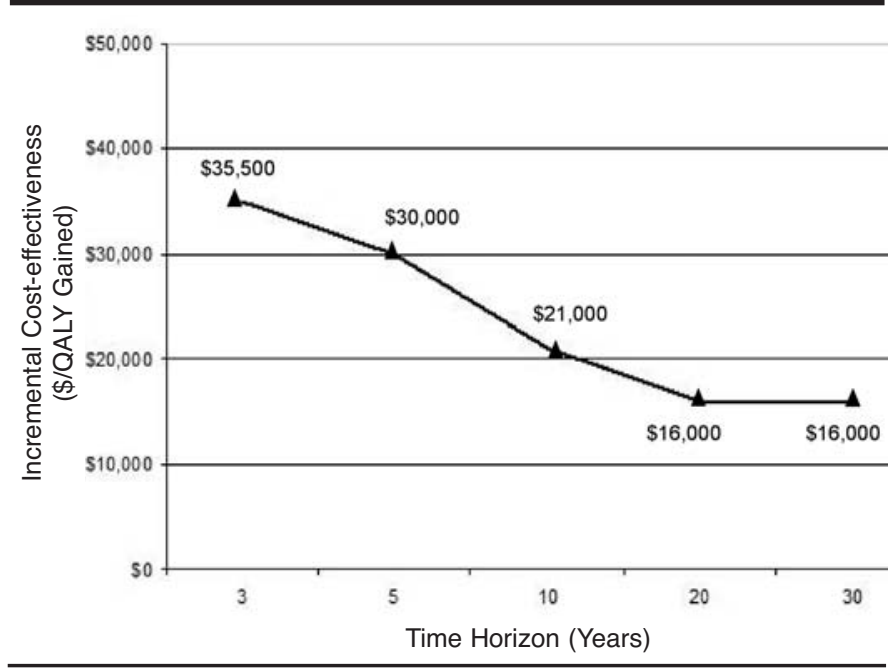

QALY = quality-adjusted life-year

clinical data existed at the time of our analysis, and inhaled insulin had not yet been launched; therefore, the pricing was not available. We also did not model liraglutide, a forthcoming competitor with the same pharmacologic mechanism as exenatide. Second, we assumed weight loss with exenatide of $8.5 \%$, considerably more than the approximate 3\% in the clinical trials at 30 weeks cited in the product label and the approximate $5 \%$ weight loss observed in the open-label observation at week 82 of follow-up for $314(57.0 \%)$ of 551 subjects randomized to exenatide and who completed 82 weeks of therapy.

Third, the decision trees in our models did not take into consideration the cost of switching to alternative therapies, though failure rates of the original treatments based on the literature are taken into consideration in the internal calculations of the CDM. Rather, we assumed that whenever a drug failed, no replacement therapy was tried. This is an oversimplification, since any treatment will always have a certain percentage of failures. While exenatide was well tolerated in the clinical trials, the aggregate dropout rate for adverse events was $4 \%$ greater with exenatide treatment than with placebo. ${ }^{14}$ Nevertheless, the difference would likely be small enough not to affect the model results, though probably larger than in the trials, where patients would have been coached to manage nausea and other side effects. We noted that the CDM user interface would have allowed us to build complex multibranch treatment decision trees, but none was preprogrammed for us, and we doubt that most payers would take the time to build them from scratch.

Finally, although we did test them to the limits of available data, our informal long-term (30-year) projections would not satisfy the methodological requirements for published pharmaco- 
economic analyses. The assumption that patients will maintain 3 BMI units (15-20 pounds) weight loss on exenatide for several years is a considerable stretch, since this time horizon extends far beyond the open-label safety extension of the phase 3 trials, from which 82-week data have been published ${ }^{22}$ and 2-year data were recently presented. ${ }^{29}$ If a more conservative BMI change assumption were entered in the CDM, the ICER results would have increased correspondingly. Also, there was an implicit assumption that no new therapeutic modalities will become available, which is certainly not the case. Also, we assumed that exenatide will at some future date be approved or widely accepted as adjunct therapy with insulin, which may not occur.

We found that, although the modeling results predicted that obese patients would be more likely to benefit from exenatide therapy, the P\&T committee chose not to include this criterion in the prior authorization criteria that they approved. This is entirely for practical reasons. Implementing such criteria would require manual review of every request for authorization, because the patient's weight and BMI are not available to Premera through electronic claims records. Manual verification would require every prescriber to fax information from the patient's chart to Premera, and neither the plan nor the provider representatives on the committee wanted to take on this extra workload. However, the modeling results still added useful information to the discussion in that we felt more confident that there was a population for whom the drug would be cost effective, even though we did not choose to micromanage the prescribing process.

It is unlikely that most health plans would take the time to learn to use the CDM as it was presented to us. Premera pharmacy staff had to spend 2 hours building scenarios that could have been created for us as defaults, so that we could simply adjust the default assumptions where we felt they were not relevant to our circumstances. The complexity and substance of the CDM are impressive, but those wishing to adapt such models for end use by payers would do well to spend considerable thought and effort designing user interfaces that could be understood by users at varying levels of expertise in pharmacoeconomics. This allows the evaluator to spend most of his/her time thinking about the validity of the clinical inputs and assumptions rather than doing data entry. With a bit of creativity, model builders can design meaningful and intuitive interfaces for novice, intermediate, and advanced end users.

The CDM is only one of several commercially available disease-based diabetes outcome models. Although its complex structure overcomes some of the inherent limitations of Markov modeling, newer object-oriented programs that have recently become available promise a more natural method of simulating the events that would actually occur in a real health care setting, recording patients' historical experiences and projecting more realistically their impact on future disease progression. ${ }^{18}$

\section{Conclusions}

This case illustrates how disease-based economic models could inform the formulary review process by predicting potential reductions in overall cost burden and suggesting subpopulations in which the drug might have greater impact. The AMCP Format is a template for presenting this information to formulary reviewers, a communication tool that facilitates transfer of objective information between the manufacturer and the reviewers who analyze the information for formulary committees. We identified a population that we expected would benefit from a trial of exenatide, but unfortunately, it is not possible to restrict use in others without resorting to a cumbersome, manual prior authorization process, requiring submission of chart data by fax. The P\&T committee chose not to impose this administrative burden.

A frequent criticism of manufacturers' models is that they are inherently biased. While it does not guarantee objectivity, use of a third-party model helps to answer this criticism. The development of modeling standards by organizations such as AMCP and ISPOR provides a framework to judge models somewhat more objectively. Health plans can either develop in-house expertise to perform the evaluations or they can contract with independent third-party pharmacoeconomists. Academic experts capable of performing independent model evaluations may be found in the pharmaceutical outcomes programs offered at many universities around the United States, and most of them are willing to serve as consultants. In addition to evaluating models, academic pharmacoeconomists can teach health plan pharmacists to perform the more straightforward evaluations themselves, if the plan wishes to develop this competency. The Foundation for Managed Care Pharmacy is also a resource for identifying experts in pharmacoeconomic modeling.

Although for practical reasons we did not use the exenatide model for this purpose, application of the model results could assist formulary committees in crafting restrictions to target appropriate patients, reducing NNT, and improving ICERs, especially in institutional settings where patient data such as weight and height are available from electronic medical records. For the manufacturer of a new product, providing a fair and well-constructed model bolsters the case for formulary adoption and helps counter the response that the plan should wait until longer-term clinical data are available before evaluating the product and deciding formulary status.

Finally, AMCP Format dossiers and the economic models within them are communication tools and function best in the context of a relationship between manufacturer and payer in which a certain level of trust has been established. Taking the time to listen carefully and responsively to the payer's specific needs for information strengthens the relationship and increases the likelihood that the model will receive more than a cursory glance. Since communication is a 2 -way process, payers must be willing to take time to meet with the manufacturer's medical and outcomes liaisons to share their information needs and provide feedback. 


\section{What is already known about this subject}

Long-term outcomes data are rarely available to assist formulary decisions for costly emerging products. Skepticism exists regarding the validity of pharmacoeconomic models generated by drug manufacturers.

\section{What this study adds}

Health plans can collaborate with manufacturers to input local assumptions in models that predict cost utility. Careful oversight of assumptions built into the core model is required in addition to review of local inputs to ensure valid output for each MCO

\section{ACKNOWLEDGMENTS}

The authors wish to thank Virginia Krause, PharmD candidate, University of Washington, for her assistance in reviewing and editing the manuscript and Alla Kommissarchik, PharmD, for reviewing the exenatide clinical data.

\section{DISCLOSURES}

No outside funding supported this study. Authors John B. Watkins and Sean D. Sullivan disclose that they are members of the AMCP Format Executive Committee and as such may have some intellectual bias in favor of submitting models. Author Michael E. Minshall discloses that he is an employee of IMS Health, the owner of the CDM model.

Watkins served as principal author of the study. Study concept and design were contributed primarily by Watkins, with input from Minshall and Sullivan. Data collection was the work of Watkins; data interpretation was the work of all authors. Writing of the manuscript was primarily the work of Watkins, with input from Minshall and Sullivan, and its revision was the work of all authors.

\section{REFERENCES}

1. The AMCP Format for Formulary Submissions Version 2.1. J Manag Care Pharm. 2005;11(5 suppl b):S1-S26. Available at: http://www.amcp.org/data/ jmcp/formatsupp.pdf. Accessed November 20, 2006.

2. Langley PC, Sullivan SD. Pharmacoeconomic evaluations: guidelines for drug purchasers. J Manag Care Pharm. 1996;2(6):671-77.

3. Mather DB, Sullivan SD, Augenstein D, Fullerton DS, Atherly D. Incorporating clinical outcomes and economic consequences into drug formulary decisions: a practical approach. Am J Manag Care. 1999;5:277-85.

4. Colmenero F, Sullivan SD, Watkins JB, Neumann PJ. Quality of clinical and economic information in evidence dossiers submitted to managed care plans in the United States. Poster presented at: 2005 ISPOR Annual International Meeting; May 15-18, 2005; Arlington, VA.

5. Colmenero F, Brauer C, Sullivan SD, Watkins JB, Neumann PJ. An audit of 106 economic analyses contained in AMCP dossier submissions, 2002-2005. Paper presented at: 2006 ISPOR Annual International Meeting; May 20-24, 2006; Philadelphia, PA.

6. Gold MR, Siegel JE, Russell LB, Weinstein MC, eds. Cost-effectiveness in Health and Medicine. Report of the Panel on Cost-Effectiveness in Health and Medicine. New York: Oxford University Press; 1996.

7. Neumann PJ. Why don't Americans use cost-effectiveness analysis? Am J Manag Care. 2004;10:308-12.

8. Bell CM, Urbach DR, Ray JG, et al. Bias in published cost effectiveness studies: systematic review. BMJ. 2006;332(7543):699-703.

9. Olson BM, Armstrong EP, Grizzle AJ, Nichter MA. Industry's perception of presenting pharmacoeconomic models to managed care organizations. J Manag Care Pharm. 2003(9)2:159-67. Available at: http://www.amcp.org/data/ jmcp/Formulary\%20Management-159-167.pdf Accessed November 20, 2006
10. Malone DC. The role of pharmacoeconomic modeling in evidence-based and value-based formulary guidelines. J Manag Care Pharm. 2005;11(4 suppl):S7-S10 Available at: http://www.amcp.org/data/jmcp/maysupp05.pdf. Accessed November 20, 2006.

11. Holman JR. FDA approves new adjunct treatment for glucose control. DOC News. 2005;2(5):9.

12. Hendry J. FDA approves exenatide. DOC News. 2005;2(7):1

13. Watkins JB, Choudhury S Roy, Wong E, Sullivan SD. Managing biotechnology in a network-model health plan: a U.S. private payer perspective. Health Aff. 2006;25(5):1347-52.

14. Byetta [prescribing information]. Amylin Pharmaceuticals, 2006. Available at: http://pi.lilly.com/us/byetta-pi.pdf. Accessed November 14, 2006

15. Anderson JW, Kendall CW, Jenkins DJ. Importance of weight management in type 2 diabetes: review with meta-analysis of clinical studies. J Am Coll Nutr. 2003;22(5):331-39.

16. Palmer AJ, Roze S, Valentine WJ, et al. The CORE diabetes model: projecting long term clinical outcomes, costs and cost-effectiveness of interventions in diabetes mellitus (types 1 and 2) to support clinical and reimbursement decision making. Curr Med Res Opin. 2004;20(suppl 1):S5-S26.

17. Palmer AJ, Roze S, Valentine WJ, et al. Validation of the CORE diabetes model against epidemiological and clinical studies. Curr Med Res Opin. 2004;20(suppl 1):S27-S40.

18. Eddy DM, Schlessinger L. Archimedes, a trial-validated model of diabetes. Diabetes Care. 2003;26:3093-3101.

19. American Diabetes Association Consensus Panel. Guidelines for computer modeling of diabetes and its complications. Diabetes Care. 2004;27(9):2262-65.

20. The Diabetes Control and Complications Trial Research Group. The effect of intensive treatment of diabetes on the development and progression of long term complications in insulin-dependent diabetes mellitus. N Engl J Med. 1993;329(14):977-86

21. UK Prospective Diabetes Study (UKPDS) Group. Intensive blood-glucose control with sulphonylureas or insulin compared with conventional treatment and risk of complication in patients with Type 2 diabetes (UKPDS 33). Lancet. 1998;352(9131):837-53.

22. Blonde L, Klein EJ, Han J, et al. Interim analysis of the effects of exenatide treatment on $\mathrm{AlC}$, weight and cardiovascular risk factors over 82 weeks in 314 overweight patients with type 2 diabetes. Diabetes Obes Metab. 2006;8: 436-47.

23. DeFronzo RA, Ratner RE, Han J, Kim DD, Fineman MS, Baron AD. Effects of exenatide (exendin-4) on glycemic control and weight over 30 weeks in metformin-treated patients with type 2 diabetes. Diabetes Care. 2005;28(5): 1092-1100.

24. Buse JB, Henry RR, Han J, Kim DD, Fineman MS, Baron AD. Effects of exenatide (exendin-4) on glycemic control over 30 weeks in sulfonylureatreated patients with type 2 diabetes. Diabetes Care. 2004;27(11):2628-35.

25. Kendall DM, Riddle MC, Rosenstock J, et al. Effects of exenatide (exendin4) on glycemic control over 30 weeks in patients with type 2 diabetes treated with metformin and a sulfonylurea. Diabetes Care. 2005;28(5):1083-91.

26. Heine RJ, Van Gaal LF, Johns D, Mihm MJ, Widel MH, Brodows RG. Exenatide versus insulin glargine in patients with suboptimally controlled type 2 diabetes: a randomized trial. Ann Intern Med. 2005;143(8):559-69.

27. Wagner EH, Sandhu N, Newton KM, McCulloch DK, MD; Ramsey SD, Grothaus LC. Effect of improved glycemic control on health care costs and utilization. JAMA. 2001;285:182-89.

28. Neumann PJ, Sullivan SD. Economic evaluation in the US: what is the missing link? Pharmacoeconomics. 2006;24(11):1163-68.

29. Henry RR, Ratner RE, Stonehouse AH, et al. Exenatide maintained glycemic control with associated weight reduction over 2 years in patients with type 2 diabetes. Poster presented at: 2006 ADA 66th Annual Scientific Sessions; June 11, 2006; Washington, DC. 